\section{POLIO POSTGRADUATE COURSE}

This most successful course was held in Johannesburg on May 20th and 21st. Seventy-nine postgraduates registered, the highest number for any course to date.

The course ws opened by Professor Underwood, Dean of The Faculty of Medicine at the University of the Witwatersrand. He spoke very appreciatively of physiotherapists and their work, and said how pleased the University was with the ever increasing popularity of the Postgraduate courses.

Dr. Haden then gave a lecture on the Kabat method of rehabilitation of muscles, particularly for polio cases. His physiotherapist, Miss Botting, helped to illustrate the lecture by a practical demonstration. Dr. Haden made it clear that only by constant practice can one understand this rather complex form of treatment which is so opposed to many more conservative forms of muscle re-education.

On Saturday morning Sister Vlok, a Sister Tutor of the Johannesburg General Hospital, gave an excellent lecture on the nursing of poliomyelitis cases. This talk was invaluable in giving a clear picture and background of the patient while being nursed through the acute stage. Sister Vlok's talk was followed by a demonstration of the more conservative methods of treatment of polio by Mrs. M. Goodman and Mrs. G. Browne, physiotherapists from Johannesburg Hospital. They demonstrated very clearly the best way of approaching the treatment of polio and showed some of the more common trick movements which can occur. This was an excellent demonstration which had been carefully prepared.

Dr. H. Malherbe of the Poliomyelitis Research Foundation then talked to us about the different types of respirator which can be used. The talk was illustrated by lantern slides and proved to be a fascinating subject. Dr. Malherbe's powers of lecturing were greatly appreciated.

In the afternoon we were lucky enough to have Dr. James Gear, of world renown, from the Poliomyelitis Research Foundation. He talked to us about the development of the polio vaccine and assessed its present day value. We were very honoured to have him give such an interesting talk.

Miss Estelle Alberts, from the Physiotherapy Department of the University, then gave a talk on the Kenny method of treatment which she had used at St. Mary's Hospital, Carshalton, in England. Miss Alberts discussed the theory of the treatment and then demonstrated the passive movements given. Her lecture was clear and well presented and she gave us the benefit of her knowledge and the ways in which she thought the Kenny method could be used.

Finally the postgraduates had the opportunity of talking to Dr. Haden's physiotherapists, as well as those from the Hospital and University so that they could practise various treatments that had been discussed in lectures, as well as exchange ideas.

Once again it was proved how important these postgraduate courses are, as Miss Emslie said when she thanked the organisers and the University. The standard of lectures and demonstrations was very high, and the co-operation of the nursing staff, particularly of the Fever Hospital, and of the doctors, could not have been bettered.

\section{PERSONAL}

Miss Margaret Emslie has gone overseas for approximately four months.

Dr. Tilly Dreyer from the Physiotherapy Department, Johannesburg General Hospital, is overseas and will be back in September.
Miss Anne Harvey, who has a private practice in London, recently spent a month in the Union and gave many people the benefit of her experience with ultrasonic therapy.

Miss Lyn Hallack has returned to Johannesburg after several months in England.

Miss Betty Ann Bouwer has left for an extended stay in England and the Continent. Town.

Miss Barbara Viney has left Johannesburg for Cape

Mr. V. Lerm is in private practice in Stellenbosch.

Miss L. Bradley has started a private practice in Port Elizabeth

Miss Fiona Paton is joining the staff of the W.N.L.A. Rehabilitation Centre in Johannesburg.

Mrs. A. I. Martienssen is working in private practice with Mr. R. Brookes.

Mr. W. E. G. Vaughan is overseas on holiday.

Mrs. V. Cohen has started a private practice in Johannesburg.

Mrs. M. Levy is now in private practice in Johannesburg.

Miss L. Pottschalk left recently to return to Germany.

Miss C. M. Taylor has gone to England to recuperate from her serious illness.

Marriage: Miss A. de Jager is to marry Mr. F. de Groen in Pretoria on July 2nd.

Mrs. W. Browne, Mrs. M. Goodman, Miss P. Tasker, Miss L. Pottschalk and Mrs. G. von Levetzow have left the staff of Johannesburg General Hospital.

Mrs. Johnston and Mrs. Stucker have joined the staff of Johannesburg General Hospital, and Miss L. Hallack, Miss S. Nicholson and Mrs. C. Levy have joined as parttime staff.

Births:

Mrs. Margaret Dodds gave birth to a son on June 8th. June.

Mrs. M. Mandel gave birth to a daughter early in 7th.

Mrs. H. Judge gave birth to a daughter on December 1955.

Mrs. P. Groves gave birth to a daughter on April 13th,

Mrs. G. Johnstone gave birth to a daughter on April 26 th, 1955.

\section{A Letter to the Editor.}

Dear Sir,

The South African Logopedic Society (Society of Speech Therapists) publishes a Journal in May and October of each year. Articles include subject matter of interest to the Physiotherapist.

Relevant contributions in the field of physiotherapy are invited.

Subscriptions are $10 /$ - per annum including postage and should be addressed to:-

The Editor,

Journal of the S.A. Logopedic Society, Witwatersrand University, Milner Park, JOHANNESBURG.

Yours faithfully, CELESTE ORDMAN.

The Editor, Journal of the S.A.L.S. 